\title{
Chemiluminescent magnetic nanoparticles with good catalytic activity and rapid separation capability and sensitive sensing for $\mathrm{H}_{2} \mathrm{O}_{2}$
}

\author{
Yuyang $\mathrm{Wu}^{1} \cdot$ Jue Wang ${ }^{1} \cdot$ Hua Cui ${ }^{1}$
}

Received: 21 June 2021 / Revised: 18 July 2021 / Accepted: 2 August 2021 / Published online: 7 August 2021

(C) Springer-Verlag GmbH Germany, part of Springer Nature 2021

\begin{abstract}
It is of considerable importance to develop chemiluminescent functionalized nanomaterials (CF-NMs) with good catalytic activity, high chemiluminescence (CL) efficiency and good stability, and rapid magnetic separation capability, achieving excellent performance in $\mathrm{CL}$ biosensing. In this study, $\mathrm{N}$-(4-aminobutyl)-N-ethylisoluminol (ABEI)-functionalized $\mathrm{CuFe}_{2} \mathrm{O}_{4} \mathrm{mag}-$ netic nanomaterial $\left(\mathrm{ABEI} / \mathrm{CuFe}_{2} \mathrm{O}_{4}\right)$ with high catalytic activity was synthesized by virtue of a solvothermal and postfunctionalization method. $\mathrm{ABEI} / \mathrm{CuFe}_{2} \mathrm{O}_{4}$ showed outstanding $\mathrm{CL}$ properties, superior to $\mathrm{ABEI}-\mathrm{CuFe}_{2} \mathrm{O}_{4}$ in liquid phase. This reveals that the immobilization of $\mathrm{ABEI}$ on the surface of $\mathrm{CuFe}_{2} \mathrm{O}_{4}$ exhibits unique heterogeneous catalytic property. The catalytic ability of $\mathrm{CuFe}_{2} \mathrm{O}_{4}$ was better than that of $\mathrm{CoFe}_{2} \mathrm{O}_{4}, \mathrm{ZnFe}_{2} \mathrm{O}_{4}, \mathrm{MnFe}_{2} \mathrm{O}_{4}$, and $\mathrm{NiFe}_{2} \mathrm{O}_{4}$. It is suggested that the peroxide-like activity as well as $\mathrm{Cu}^{2+}$ and $\mathrm{Cu}^{0}$ enriched on the surface of $\mathrm{ABEI} / \mathrm{CuFe}_{2} \mathrm{O}_{4}$ opened up a dual route for synergistic catalysis of $\mathrm{H}_{2} \mathrm{O}_{2}$. ABEI/CuFe $\mathrm{O}_{4}$ also demonstrated good superparamagnetism and magnetic separation could be carried out in $2 \mathrm{~min}$, which is advantageous for the separation and purification of $\mathrm{ABEI} / \mathrm{CuFe} \mathrm{O}_{4}$ during the synthetic procedures and bioassays. Owing to the sensitive response of $\mathrm{ABEI} / \mathrm{CuFe}_{2} \mathrm{O}_{4}$ to $\mathrm{H}_{2} \mathrm{O}_{2}$, an enzyme-free sensor was developed for the detection of $\mathrm{H}_{2} \mathrm{O}_{2}$ with a wide linear range over 5 orders of magnitude of $\mathrm{H}_{2} \mathrm{O}_{2}$ concentrations and a low detection limit of $5.6 \mathrm{nM}$. The asdeveloped sensor is sensitive, stable, and convenient. This work provides a new family member of nanomaterials with good magnetism and CL activity as well as good stability. The developed $\mathrm{ABEI} / \mathrm{CuFe} \mathrm{O}_{4}$ shows great prospects in biocatalysis, bioassays, biosensing, and bioimaging, etc.
\end{abstract}

Keywords Chemiluminescence $\cdot$ Magnetic nanomaterials $\cdot$ Catalytic activity $\cdot$ Sensor

\section{Introduction}

Over the past decade, chemiluminescent functionalized nanomaterials (CF-NMs) have received great interests in bioassays due to their excellent CL properties, ease-to-assemble, and good biocompatibility [1-4]. They have been used as nanoprobes and nanointerfaces to develop various

Published in the topical collection celebrating ABCs 20th Anniversary.

Jue Wang

wj0422@mail.ustc.edu.cn

Hua Cui

hcui@ustc.edu.cn

1 CAS Key Laboratory of Soft Matter Chemistry, Collaborative Innovation Center of Chemistry for Energy Materials, Department of Chemistry, University of Science and Technology of China, Hefei, Anhui 230026, People's Republic of China methodologies for immunoassays and nucleic acid assays, which have greatly improved the analytical performance [5-9]. Nevertheless, some CF-NMs do not have high CL efficiency on their own and usually need to modify extra catalysts to improve their performance. In that case, not only the modification steps are required, but also the stability of CFNMs cannot be guaranteed. In addition, conventional CFNMs often require complicated purification procedures, such as filtration, dialysis, or centrifugation, which greatly prolong the analysis time and may also influence the analytical accuracy. Therefore, it is highly desired to develop CF-NMs with good catalytic activity, high CL efficiency, and good stability, achieving excellent performance in CL biosensing.

It is worth noting that magnetic nanomaterials (MNMs) deploy extensive applications in the fields of bioassay, biomedicine, catalysis, and energy storage [10-13]. Benefiting from their tunable chemical composition, intrinsic magnetism, and large specific surface area, MNMs can be considered as 
nanoplatforms in CL bioassays [14-16]. To date, various magnetic materials as carriers have been used for the development of CF-NMs, such as magnetic mesoporous carbon materials [17], $\mathrm{Fe}_{3} \mathrm{O}_{4}$ magnetic beads [18], magnetic graphene materials [19], and magnetic hydrogels [20]. Among them, CF-NMs without catalysts often possess relatively low CL efficiency, while others loaded with catalysts exhibit improved CL performance. However, it is tedious to modify the catalyst, which is also easy to leak. On the other hand, some MNMs have catalytic properties due to their special chemical composition. Among them, $\mathrm{MFe}_{2} \mathrm{O}_{4}(\mathrm{M}=\mathrm{Cu}, \mathrm{Co}, \mathrm{Mn}, \mathrm{Ni}$, and $\mathrm{Zn})$ with a spinel structure have received wide attention. The catalytic effect of $\mathrm{MFe}_{2} \mathrm{O}_{4}$ on luminol CL reactions has been reported [21-23]. To the best of our knowledge, $\mathrm{MFe}_{2} \mathrm{O}_{4}$ has not been used as a carrier to synthesize $\mathrm{CF}-\mathrm{NMs}$. Considering inherent catalytic activity and superparamagnetism of $\mathrm{MFe}_{2} \mathrm{O}_{4}, \mathrm{MFe}_{2} \mathrm{O}_{4}$ may be utilized directly loading $\mathrm{CL}$ reagents to develop highly efficient CFNMs without additional loading of catalysts.

Herein, we synthesized ABEI-functionalized $\mathrm{CuFe}_{2} \mathrm{O}_{4}$ magnetic nanoparticles $\left(\mathrm{ABEI} / \mathrm{CuFe}_{2} \mathrm{O}_{4}\right)$ by using a solvothermal and post-functionalization method. The asprepared $\mathrm{ABEI} / \mathrm{CuFe}{ }_{2} \mathrm{O}_{4}$ was characterized by highresolution transmission electron microscopy (HRTEM), scanning electron microscopy (SEM), X-ray photoelectron spectroscopy (XPS), X-ray diffraction (XRD), inductively coupled plasma-atomic emission spectrometry (ICP-AES), and ultraviolet-visible (UV-vis) absorption spectroscopy. The assynthesized $\mathrm{ABEI} / \mathrm{CuFe} \mathrm{O}_{2} \mathrm{O}_{4}$ showed good $\mathrm{CL}$ performance and superparamagnetism. The effect of various factors on CL properties of $\mathrm{ABEI} / \mathrm{CuFe}_{2} \mathrm{O}_{4}$ was examined. The CL behavior of various ferrite/ABEI with different transition metal element was compared, including $\mathrm{CuFe}_{2} \mathrm{O}_{4}, \mathrm{CoFe}_{2} \mathrm{O}_{4}$, $\mathrm{ZnFe}_{2} \mathrm{O}_{4}, \mathrm{MnFe}_{2} \mathrm{O}_{4}$, and $\mathrm{NiFe}_{2} \mathrm{O}_{4}$. A dual route pioneered by $\mathrm{CuFe}_{2} \mathrm{O}_{4}$ as well as surface-rich $\mathrm{Cu}^{2+}$ and $\mathrm{Cu}^{0}$ for synergistic catalysis mechanism has been proposed. Moreover, based on sensitive $\mathrm{CL}$ response of $\mathrm{ABEI} / \mathrm{CuFe}_{2} \mathrm{O}_{4}$ to $\mathrm{H}_{2} \mathrm{O}_{2}$, an enzyme-free sensor was constructed for detection of $\mathrm{H}_{2} \mathrm{O}_{2}$. The applicability of the $\mathrm{H}_{2} \mathrm{O}_{2}$ sensor in human serum samples was explored.

\section{Experimental section}

\section{Chemicals and materials}

Copper chloride dihydrate $\left(\mathrm{CuCl}_{2} \cdot 2 \mathrm{H}_{2} \mathrm{O}\right)$, iron chloride hexahydrate $\left(\mathrm{FeCl}_{3} \cdot 6 \mathrm{H}_{2} \mathrm{O}\right)$, sodium acetate $(\mathrm{NaAc})$, trisodium citrate dihydrate $\left(\mathrm{Na}_{3} \mathrm{Cit} \cdot 2 \mathrm{H}_{2} \mathrm{O}\right)$, and ethylene glycol were purchased from Sinopharm Chemical Reagent Co. (Shanghai, China). Four millimolars of ABEI stock solution was obtained by dissolving ABEI (TCI, Japan) in $0.1 \mathrm{M} \mathrm{NaOH}$ solution and stored in a dark environment at $4{ }^{\circ} \mathrm{C} . \mathrm{H}_{2} \mathrm{O}_{2}(30 \%, v / v)$ was provided by Xinke Chemical Reagent Factory (Bengbu, China) and diluted freshly before CL measurement. The reagents involved in the experiments were of analytical grade. The ultrapure water was obtained from a Milli-Q system (Millipore, France). Human serum samples were obtained from Anhui Chest Hospital.

\section{Synthesis of $\mathrm{ABEI} / \mathrm{CuFe}_{2} \mathrm{O}_{4}$}

$\mathrm{CuFe}_{2} \mathrm{O}_{4}$ was prepared by referring to a previous work [24] with some modifications as follows. First, $0.2556 \mathrm{~g} \mathrm{CuCl}_{2}$. $2 \mathrm{H}_{2} \mathrm{O}$ and $0.81 \mathrm{~g} \mathrm{FeCl}_{3} \cdot 6 \mathrm{H}_{2} \mathrm{O}$ were dissolved in $20 \mathrm{~mL}$ ethylene glycol solution at room temperature. After the solution was clear, $1.64 \mathrm{~g} \mathrm{NaAc}$ and a certain amount of $\mathrm{Na}_{3} \mathrm{Cit} \cdot 2 \mathrm{H}_{2} \mathrm{O}$ were added and stirred for $2 \mathrm{~h}$. The obtained solution was transferred to an autoclave and subsequently placed at $200{ }^{\circ} \mathrm{C}$ for $16 \mathrm{~h}$. After the reaction, the product was washed several times using ultrapure water and ethanol alternately. The precipitate was dried under vacuum for $6 \mathrm{~h}$ and stored at $4{ }^{\circ} \mathrm{C}$. Next, $10 \mathrm{mg}$ of the obtained powder was dispersed in ultrapure water by ultrasonication. Then, $\mathrm{CuFe}_{2} \mathrm{O}_{4}$ dispersion, ultrapure water, and $\mathrm{ABEI}$ solution were mixed by the volume ratio of $2: 1: 1$. After shaking for $12 \mathrm{~h}$, the mixture was magnetically separated. The resulted $\mathrm{ABEI} / \mathrm{CuFe}_{2} \mathrm{O}_{4}$ was washed three times and then dispersed in ultrapure water and placed at $4{ }^{\circ} \mathrm{C}$ for further use.

\section{Characterizations}

The morphology of $\mathrm{ABEI} / \mathrm{CuFe}_{2} \mathrm{O}_{4}$ was characterized by HRTEM (Talos F200X, FEI, USA). The SEM image of the nanomaterials was recorded by a cold field emission scanning electron microscopy (SU8220, Hitachi, Japan). The XPS data was obtained using X-ray photoelectron spectroscopy (ESCALAB 250Xi, VG Scientific, UK) with $\mathrm{Al} \mathrm{K} \alpha$ radiation $(\mathrm{h} v=1486.6 \mathrm{eV})$ as the $\mathrm{X}$-ray excitation source. The XRD spectra was scanned by an X-ray powder diffractometer (MiniFlex600, Rigaku, Japan) with $\mathrm{Cu} \mathrm{K} \alpha$ radiation $(\lambda=$ $0.15406 \mathrm{~nm}$ ). The elemental composition was measured by ICP-AES (OPTIMA 7000DV, PerkinElmer, USA). The loading efficiency of ABEI was measured by UV-vis spectrophotometer (Agilent 8453, Agilent Technologies, USA). The CL spectrum was performed on a fluorescence spectrophotometer with the lamp off (F-7000, Hitachi, Japan). The data of the hysteresis curve was measured in the magnetic measurement system (MPMS3, Quantum Design, USA). The chemical bonds in the nanomaterials were analyzed with Fouriertransform infrared spectroscopy (FTIR) (EQUINX55, Broker, Germany). 


\section{CL measurements}

The measurements of CL kinetics, condition optimization, and stability were performed on a Centro LB 960 microplate luminometer (Berthold, Germany). The investigation of the $\mathrm{CL}$ mechanism of the nanomaterials was carried out on a CL detector (LUMIstar Omega, BMG LABTECH, Germany). Typically, $50 \mu \mathrm{L}$ of $\mathrm{ABEI} / \mathrm{CuFe}_{2} \mathrm{O}_{4}$ dispersion was injected into a 96-well microplate, and $50 \mu \mathrm{L}$ of $\mathrm{H}_{2} \mathrm{O}_{2}$ alkaline solution was introduced as a co-reacting reagent. Generally, the $\mathrm{CL}$ signal was recorded every $0.1 \mathrm{~s}$ within $30 \mathrm{~s}$, and the integrated intensity of the nanomaterials was recorded.

\section{Procedures for serum samples}

The human serum samples were processed as follows. Firstly, $20 \mu \mathrm{L}$ of human serum was diluted to $2 \mathrm{~mL}$ with ultrapure water. The diluted sample was then centrifuged with an ultrafiltration tube at $4000 \mathrm{rpm}$ for $5 \mathrm{~min}$ at $4{ }^{\circ} \mathrm{C}$ to thoroughly remove precipitates. After purification, CL measurements were performed immediately. In a recovery experiment, a certain concentration of $\mathrm{H}_{2} \mathrm{O}_{2}$ was added to samples, and processed according to the above steps.

\section{Results and discussion}

\section{Synthesis and characterizations}

$\mathrm{ABEI} / \mathrm{CuFe}_{2} \mathrm{O}_{4}$ was synthesized by a solvothermal method with post-functionalization. The synthesis steps are briefly shown in Scheme 1. During the synthesis of $\mathrm{CuFe}_{2} \mathrm{O}_{4}$, the molar ratio of $\mathrm{CuCl}_{2} \cdot 2 \mathrm{H}_{2} \mathrm{O}$ to $\mathrm{FeCl}_{3} \cdot 6 \mathrm{H}_{2} \mathrm{O}$ was $1: 2 . \mathrm{Na}_{3} \mathrm{Cit}$ $2 \mathrm{H}_{2} \mathrm{O}$ was used as an electrostatic stabilizer, and $\mathrm{NaAc}$ was

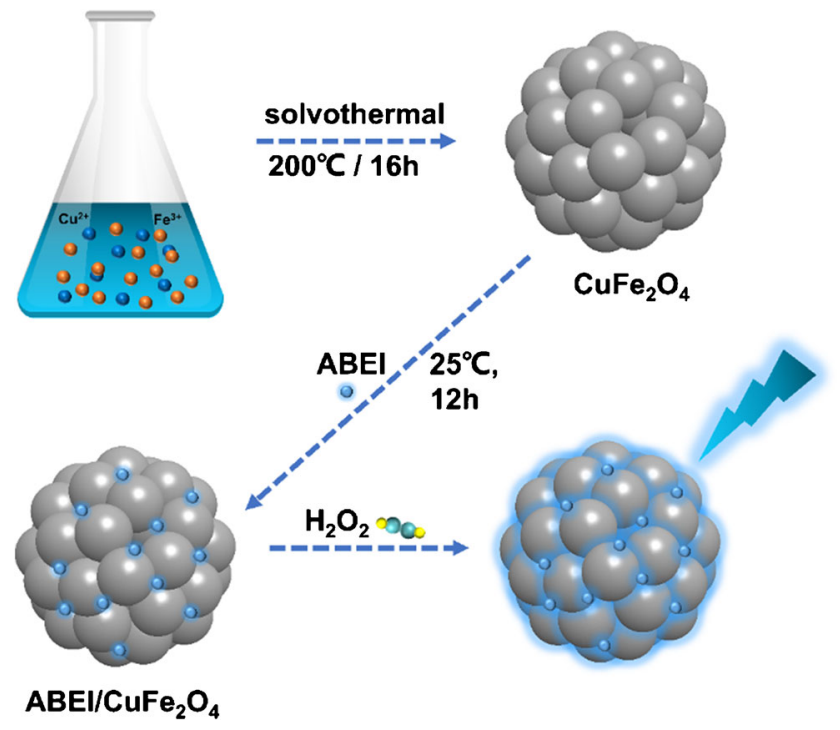

Scheme 1 Schematic diagram of the synthesis of $\mathrm{ABEI} / \mathrm{CuFe} \mathrm{O}_{4}$ used to adjust the $\mathrm{pH}$ of the reaction solution. Ethylene glycol was used as a reducing agent, which also provided a stable solvent environment to prevent from agglomeration at high temperature and generate $\mathrm{CuFe}_{2} \mathrm{O}_{4}$. After purification and drying, the product was redispersed in water, followed by shaking with ABEI for $12 \mathrm{~h}$. Under neutral conditions, the final product $\mathrm{ABEI} / \mathrm{CuFe} \mathrm{O}_{2}$ was obtained.

The size and morphology of $\mathrm{ABEI} / \mathrm{CuFe}_{2} \mathrm{O}_{4}$ nanomaterials were observed by HRTEM and SEM. HRTEM (Fig. 1A) demonstrated that the nanomaterials were well-dispersed quasi-spheres with a relatively uniform particle size and an average diameter of about $97.5 \pm 7.2 \mathrm{~nm}$, which was roughly consistent with the SEM image (see Supplementary Information (ESM) Fig. S1). In addition, the surface of the nanoparticles was slightly rough to provide more adsorption sites. In Fig. $1 \mathrm{~B}$, the measured spacings of two adjacent planes in different directions were $0.30 \mathrm{~nm}$ and $0.25 \mathrm{~nm}$, which corresponded finely to the lattice spacings in the (220) and (311) planes of $\mathrm{CuFe}_{2} \mathrm{O}_{4}$, respectively. To further investigate the elemental composition and distribution of $\mathrm{ABEI} / \mathrm{CuFe}_{2} \mathrm{O}_{4}$, elemental mapping was performed. It could be seen in Fig. 1D-H that $\mathrm{Cu}, \mathrm{Fe}, \mathrm{O}$, and $\mathrm{N}$ elements existed on the nanomaterials, which confirmed the successful preparation of $\mathrm{CuFe}_{2} \mathrm{O}_{4}$ and the subsequent effective adsorption of ABEI.

The crystalline phase structure of the nanomaterials was further determined by XRD measurements (Fig. 2). The positions and relative intensities of the diffraction peaks appearing in the synthesized $\mathrm{CuFe}_{2} \mathrm{O}_{4}$ (a) and $\mathrm{ABEI} / \mathrm{CuFe}_{2} \mathrm{O}_{4}$ (b) did not change significantly, which showed that the addition of ABEI did not destroy the crystalline structure of $\mathrm{CuFe}_{2} \mathrm{O}_{4}$. The peaks at $2 \theta=18.3^{\circ}, 30.2^{\circ}, 35.6^{\circ}, 43.3^{\circ}, 57.0^{\circ}$, and $62.7^{\circ}$ in the spectra represented the crystallographic planes of cubic crystals $\mathrm{CuFe}_{2} \mathrm{O}_{4}$ at (111), (220), (311), (400), (511), and (440), respectively. Strikingly, it was also observed that the peaks at $2 \theta=43.3^{\circ}, 50.4^{\circ}$, and $74.1^{\circ}$ corresponded to the (111), (200), and (220) diffraction planes of fcc $\mathrm{Cu}$ crystals. This was due to the excess presence of ethylene glycol as a strong reducing agent during the synthesis of $\mathrm{CuFe}_{2} \mathrm{O}_{4}$ by the solvothermal method at high temperatures, which made it possible that $\mathrm{Cu}^{2+}$ could be reduced to $\mathrm{Cu}^{0}[25,26]$.

XPS was taken to further confirm the composition and elemental valence state in the nanomaterials. As shown in ESM Fig. S2, after the addition of ABEI, $\mathrm{Fe}, \mathrm{Cu}, \mathrm{O}, \mathrm{C}$, and $\mathrm{N}$ elements were found in the nanomaterials, which indicated the successful modification of ABEI. The component and content of the nanomaterials were determined by UV-vis as well as ICP-AES. $\mathrm{CuFe}_{2} \mathrm{O}_{4}$ had a wide absorption band between 200 and $1000 \mathrm{~nm}$, while two characteristic absorption peaks of ABEI were located near $291 \mathrm{~nm}$ and $320 \mathrm{~nm}$ (ESM Fig. S3A). The UV-vis curve of $\mathrm{ABEI} / \mathrm{CuFe}_{2} \mathrm{O}_{4}$ demonstrated broad absorption band of $\mathrm{CuFe}_{2} \mathrm{O}_{4}$ and two characteristic absorption peaks of $\mathrm{ABEI}$, which proved again that $\mathrm{ABEI}$ had been successfully modified to the surface of $\mathrm{CuFe}_{2} \mathrm{O}_{4}$ 


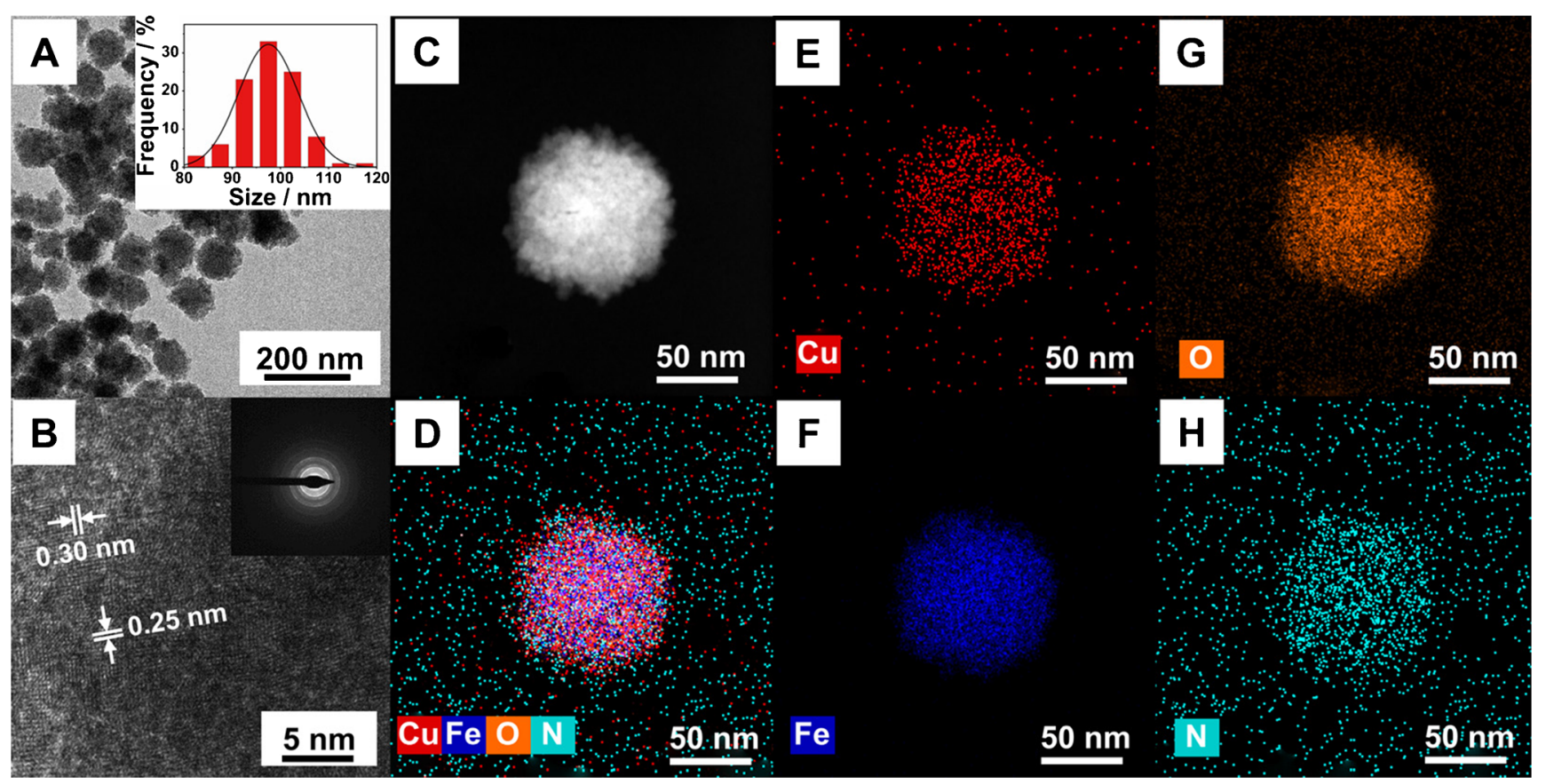

Fig. 1 A HRTEM image of ABEI/CuFe $\mathrm{O}_{4}$. B Lattice-resolved HRTEM image of $\mathrm{ABEI} / \mathrm{CuFe} \mathrm{O}_{4}$. C HAADF image of $\mathrm{ABEI} / \mathrm{CuFe} \mathrm{O}_{4}$. D Elemental mapping image of $\mathrm{ABEI} / \mathrm{CuFe}_{2} \mathrm{O}_{4}(\mathrm{Cu}, \mathrm{Fe}, \mathrm{O}, \mathrm{N})$ and

nanospheres. In addition, ABEI loaded on the nanomaterials was about $52.0 \%$. Moreover, the contents of $\mathrm{Cu}$ and $\mathrm{Fe}$ in $\mathrm{ABEI} / \mathrm{CuFe}_{2} \mathrm{O}_{4}$ were calculated to be $272.5 \mathrm{mg} / \mathrm{g}$ and $304.0 \mathrm{mg} / \mathrm{g}$ by ICP-AES, respectively.

The assembly mechanism of $\mathrm{ABEI} / \mathrm{CuFe}_{2} \mathrm{O}_{4}$ was discussed in detail. As shown in FTIR (ESM Fig. S4), the peak position at $3446 \mathrm{~cm}^{-1}$ was a typical $-\mathrm{OH}$ peak [24], indicating the presence of a large number of oxygencontaining functional groups on the surface of $\mathrm{CuFe}_{2} \mathrm{O}_{4}$, which facilitated the subsequent functionalization of the molecule. Since the ABEI molecule contained $-\mathrm{NH}_{2}$ and $\mathrm{CuFe}_{2} \mathrm{O}_{4}$

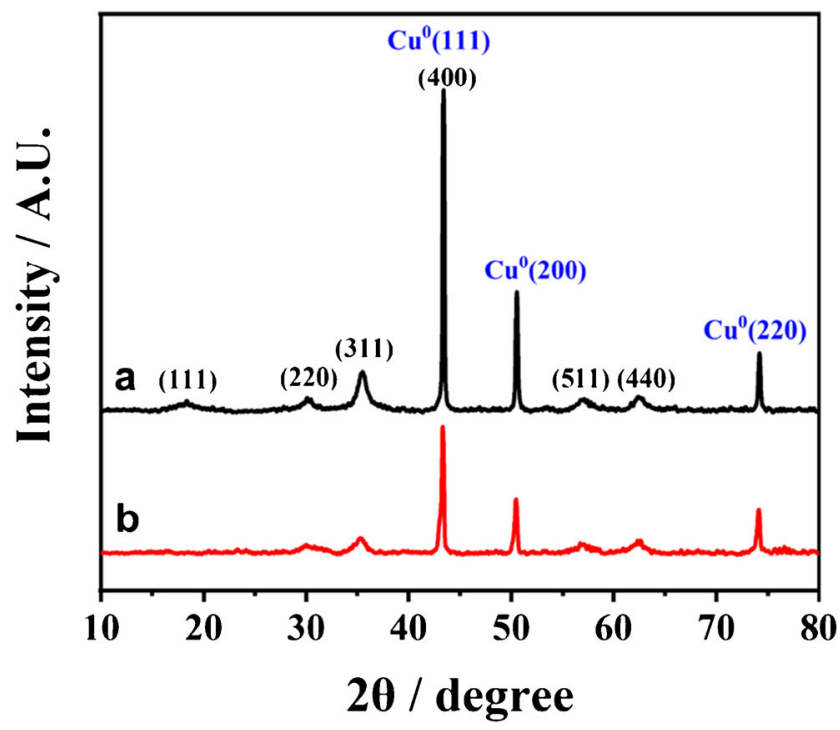

Fig. 2 XRD spectra of $\mathrm{CuFe}_{2} \mathrm{O}_{4}$ (a) and $\mathrm{ABEI} / \mathrm{CuFe}_{2} \mathrm{O}_{4}$ (b)

corresponding single element distribution of $\mathbf{E ~ C u}, \mathbf{F ~ F e}, \mathbf{G ~ O}$, and $\mathbf{H}$ $\mathrm{N}$. Inset in $\mathbf{A}$ : particle size statistics of $\mathrm{ABEI} / \mathrm{CuFe}_{2} \mathrm{O}_{4}$. Inset in $\mathbf{B}$ : selected area electron diffraction pattern of $\mathrm{ABEI} / \mathrm{CuFe}_{2} \mathrm{O}_{4}$

possessed abundant $-\mathrm{OH}$, the hydrogen bonding interactions were likely to occur between the two groups $[27,28]$. Furthermore, the surface of $\mathrm{CuFe}_{2} \mathrm{O}_{4}$ contained $\mathrm{Cu}^{2+}$ and $\mathrm{Cu}^{0}$, which allowed $\mathrm{ABEI}$ to coordinate with $\mathrm{Cu}$ elements. Therefore, it was suggested that ABEI could be connected on the surface of the nanomaterials by the hydrogen bonding between the hydroxyl group of $\mathrm{CuFe}_{2} \mathrm{O}_{4}$ and the amino group of $\mathrm{ABEI}$ and the coordination between $\mathrm{Cu}$ element and the amino group of ABEI.

\section{Magnetic property of $\mathrm{ABEI} / \mathrm{CuFe}_{2} \mathrm{O}_{4}$}

The hysteresis test curves of $\mathrm{CuFe}_{2} \mathrm{O}_{4}$ and $\mathrm{ABEI} / \mathrm{CuFe}_{2} \mathrm{O}_{4}$ collected at room temperature are shown in Fig. 3. The above nanomaterials were both free of hysteresis and showed excellent superparamagnetism. The saturation magnetization strengths of $\mathrm{CuFe}_{2} \mathrm{O}_{4}$ and $\mathrm{ABEI} / \mathrm{CuFe}_{2} \mathrm{O}_{4}$ are $39.01 \mathrm{emu} / \mathrm{g}$ and $38.36 \mathrm{emu} / \mathrm{g}$, respectively, which did not change. Under the force of an applied magnet, $\mathrm{ABEI} / \mathrm{CuFe}_{2} \mathrm{O}_{4}$ could be separated simply from the aqueous phase within $2 \mathrm{~min}$.

\section{$\mathrm{CL}$ behavior of $\mathrm{ABEI} / \mathrm{CuFe}_{2} \mathrm{O}_{4}$}

The CL properties of $\mathrm{ABEI} / \mathrm{CuFe}_{2} \mathrm{O}_{4}$ were studied on a microplate luminometer. As shown in Fig. 4A, when $\mathrm{ABEI} / \mathrm{CuFe}_{2} \mathrm{O}_{4}$ reacted with $\mathrm{H}_{2} \mathrm{O}_{2}$, strong light emission was observed, which was 397 times that of $\mathrm{ABEI}-\mathrm{H}_{2} \mathrm{O}_{2}$ system. When the mixture of $\mathrm{ABEI}$ and $\mathrm{CuFe}_{2} \mathrm{O}_{4}$ reacted with $\mathrm{H}_{2} \mathrm{O}_{2}$, much weaker CL emission was generated, but it was 


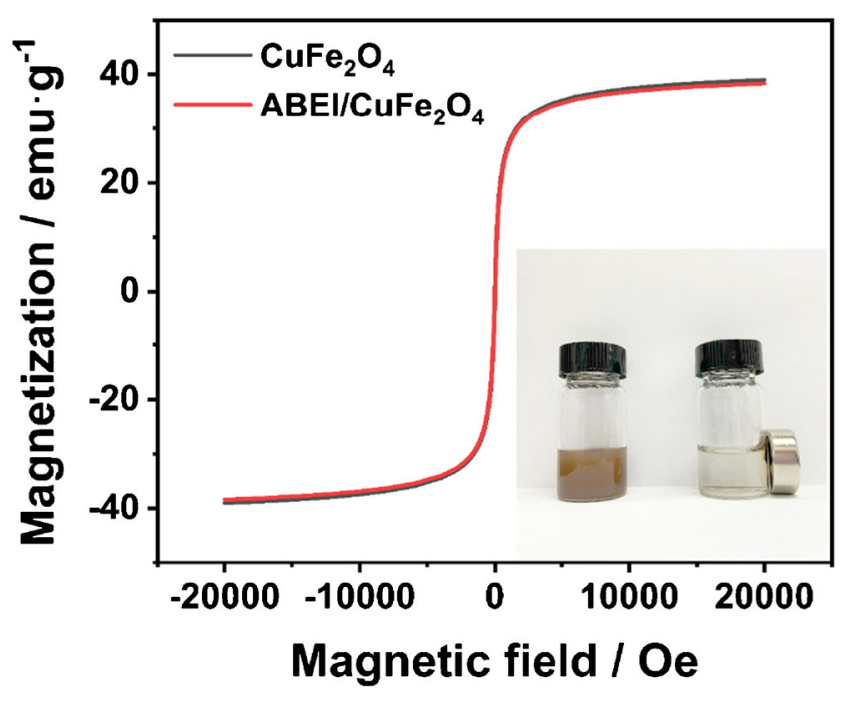

Fig. 3 Hysteresis test curves of $\mathrm{CuFe}_{2} \mathrm{O}_{4}$ and $\mathrm{ABEI} / \mathrm{CuFe} \mathrm{O}_{4}$ at room temperature. Insert: magnetic separation of $\mathrm{ABEI} / \mathrm{CuFe}_{2} \mathrm{O}_{4}$ under the condition of applied magnet

also 220 times that of ABEI- $\mathrm{H}_{2} \mathrm{O}_{2}$ system. The results implied that the immobilization of ABEI on the surface of $\mathrm{CuFe}_{2} \mathrm{O}_{4}$ was beneficial for the $\mathrm{CL}$ emission. Furthermore, instead of $\mathrm{CuFe}_{2} \mathrm{O}_{4}, \mathrm{Fe}_{3} \mathrm{O}_{4}$ was used to prepare $\mathrm{ABEI} / \mathrm{Fe}_{3} \mathrm{O}_{4}$. The $\mathrm{CL}$ intensity of $\mathrm{ABEI} / \mathrm{Fe}_{3} \mathrm{O}_{4}-\mathrm{H}_{2} \mathrm{O}_{2}$ system was only $13 \%$ of that of $\mathrm{ABEI} / \mathrm{CuFe} \mathrm{O}_{4}-\mathrm{H}_{2} \mathrm{O}_{2}$ system. This result demonstrated that cupper played an important role in the CL emission. The CL spectra of $\mathrm{ABEI} / \mathrm{CuFe}_{2} \mathrm{O}_{4}$ and $\mathrm{ABEI}$ reacting with $\mathrm{H}_{2} \mathrm{O}_{2}$ are presented in Fig. 4B. It was found that maximum $\mathrm{CL}$ emission of $\mathrm{ABEI} / \mathrm{CuFe}_{2} \mathrm{O}_{4}$ was around $445 \mathrm{~nm}$, which was consistent with that of $\mathrm{ABEI}-\mathrm{H}_{2} \mathrm{O}_{2} \mathrm{CL}$ system, indicating that the $\mathrm{CL}$ emission of the nanomaterials was generated by the reaction of ABEI with $\mathrm{H}_{2} \mathrm{O}_{2}$ [29].
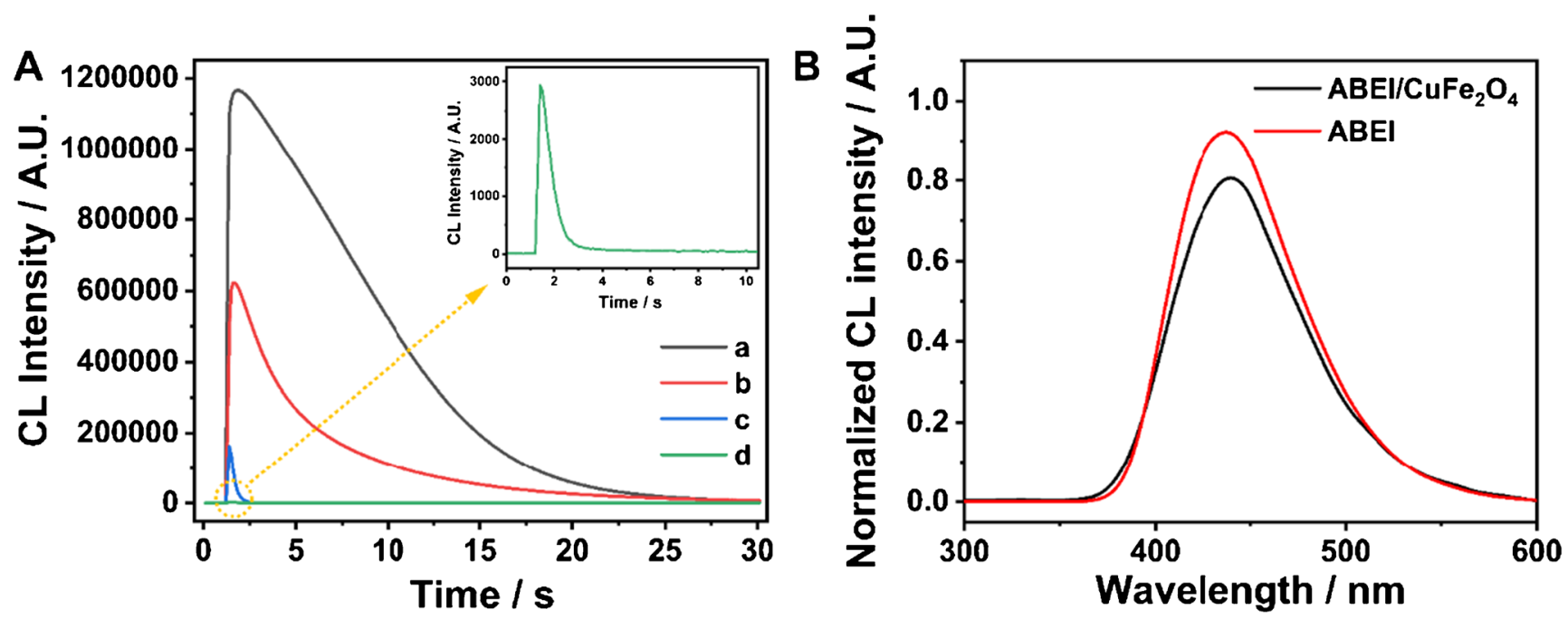

Fig. 4 A CL kinetic curves of $\mathrm{ABEI} / \mathrm{CuFe}_{2} \mathrm{O}_{4}$ (a), $\mathrm{ABEI}$ mixed with $\mathrm{CuFe}_{2} \mathrm{O}_{4}$ in liquid phase (b), $\mathrm{ABEI} / \mathrm{Fe}_{3} \mathrm{O}_{4}$ (c), and $\mathrm{ABEI}$ (d). B CL spectra of $\mathrm{ABEI} / \mathrm{CuFe}_{2} \mathrm{O}_{4}$ and $\mathrm{ABEI}$ 


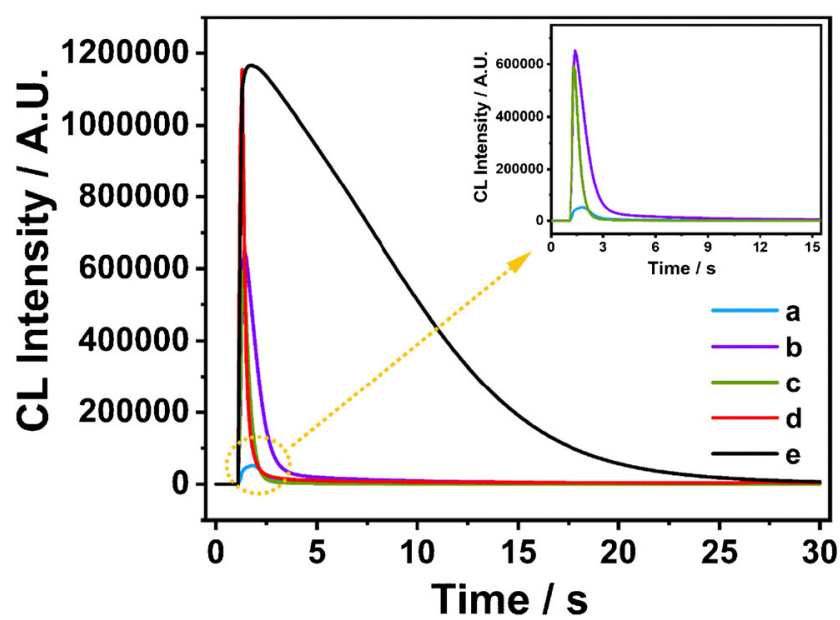

Fig. 5 Comparison of the CL kinetic curves of $\mathrm{ABEI} / \mathrm{MFe}_{2} \mathrm{O}_{4} \cdot \mathrm{M}=\mathrm{Mn}$ (a), $\mathrm{Zn}$ (b), $\mathrm{Ni}$ (c), $\mathrm{Co}$ (d), $\mathrm{Cu}$ (e)

obtained. Minor fluctuations in the measured signal values around 1,150,000 A.U. were observed. The relative standard deviations (R.S.D.) of the measured CL signals were calculated to be $1.2 \%, 1.3 \%$, and $1.2 \%$ for repeated measurements within a day and within a month and between 5 batches, respectively. The above results indicated that the synthesized $\mathrm{ABEI} / \mathrm{CuFe}_{2} \mathrm{O}_{4}$ possessed good CL stability.

\section{$\mathrm{CL}$ reaction mechanism of $\mathrm{ABEl} / \mathrm{CuFe}_{2} \mathrm{O}_{4}$ with $\mathrm{H}_{2} \mathrm{O}_{2}$}

The as-prepared $\mathrm{ABEI} / \mathrm{CuFe}_{2} \mathrm{O}_{4}$ nanomaterials exhibited superior CL properties, which might be related to the surface catalytic properties of $\mathrm{CuFe}_{2} \mathrm{O}_{4}$ nanospheres. It was reported that the enhancement of the ABEI CL system by catalysts was due to the catalysts could facilitate the formation of CL intermediates such as superoxide radicals $\left(\mathrm{O}_{2}{ }^{-}\right)$and hydroxyl radicals $(\mathrm{OH} \bullet)$. Previously, it was also reported that $\mathrm{CuFe}_{2} \mathrm{O}_{4}$ with peroxidase-like catalytic activity could catalyze the decomposition of $\mathrm{H}_{2} \mathrm{O}_{2}$ to generate $\mathrm{OH} \bullet$, which was beneficial to enhance the efficiency of CL reactions [30]. Besides, $\mathrm{Cu}^{2+}$ and $\mathrm{Cu}^{0}$ was able to produce $\mathrm{OH} \bullet$ indirectly in the presence of $\mathrm{H}_{2} \mathrm{O}_{2}$ [31-33]. It was speculated that $\mathrm{CuFe}_{2} \mathrm{O}_{4}, \mathrm{Cu}^{2+}$, and $\mathrm{Cu}^{0}$ may facilitate the generation of $\mathrm{O}_{2}{ }^{-}$and $\mathrm{OH} \bullet$ during ABEI $\mathrm{CL}$ reaction, leading to high $\mathrm{CL}$ efficiency.

To determine whether or not the dissolved oxygen, $\mathrm{O}_{2}{ }^{-}$, and $\mathrm{OH} \cdot$ were involved in the $\mathrm{CL}$ reaction, the effects of nitrogen $\left(\mathrm{N}_{2}\right)$, oxygen $\left(\mathrm{O}_{2}\right)$, and two free radical scavengers superoxide dismutase (SOD) and thiourea on the CL intensity were investigated. As shown in ESM Fig. S12A, the CL intensity increased at $\mathrm{O}_{2}$-saturated solution (red curve) and decreased at $\mathrm{N}_{2}$-saturated solution, compared with that at an air atmosphere. This result indicated that dissolved oxygen $\left(\mathrm{O}_{2}\right)$ was involved in the CL reaction of the nanomaterials. Moreover, as shown in ESM Fig. S12B\&C, the quenching effect on the CL signal became obvious along with the continuous increase of the concentration of free radical scavengers SOD and thiourea, suggesting that $\mathrm{O}_{2}{ }^{-}$and $\mathrm{OH} \bullet$ took part in the CL reaction. Accordingly, $\mathrm{CuFe}_{2} \mathrm{O}_{4}, \mathrm{Cu}^{2+}$, and $\mathrm{Cu}^{0}$ did facilitate the generation of $\mathrm{O}_{2}{ }^{-}$and $\mathrm{OH} \bullet$ during $\mathrm{ABEI} C L$ reaction, resulting in strong light emission. The CL mechanism is suggested as shown in Fig. 6.

\section{Detection of $\mathrm{H}_{2} \mathrm{O}_{2}$}

Hydrogen peroxide $\left(\mathrm{H}_{2} \mathrm{O}_{2}\right)$ is not only a by-product of active oxygen metabolism in organisms, but also a key regulator of various oxidative stress-related states. It is closely related to the occurrence and development of some diseases [34, 35]. Therefore, it is very important to develop stable and efficient $\mathrm{H}_{2} \mathrm{O}_{2}$ detection methodologies. In view of the excellent $\mathrm{CL}$ behavior of $\mathrm{ABEI} / \mathrm{CuFe} \mathrm{O}_{4}$ and its sensitive response to $\mathrm{H}_{2} \mathrm{O}_{2}$, a non-enzymatic $\mathrm{H}_{2} \mathrm{O}_{2}$ sensor was constructed. Under the optimal experimental conditions, $\mathrm{H}_{2} \mathrm{O}_{2}$ solution was diluted at different concentrations. As shown in Fig. 7A, the CL intensity was linear with $\mathrm{H}_{2} \mathrm{O}_{2}$ concentration in the range of $10.0 \mathrm{nM}$ to $0.1 \mathrm{mM}$. The linear regression equation was fitted as $I_{\text {integrated }}=661746.0 \times \mathrm{C}\left(\mathrm{H}_{2} \mathrm{O}_{2}\right)+33355.5$, and the correlation coefficient $\left(R^{2}\right)$ was 0.999 . The limit of detection (LOD) could be as low as $5.6 \mathrm{nM}$ when the signal-to-noise ratio $(\mathrm{S} / \mathrm{N})$ was 3. Table S1 (see ESM) summarized several representative non-enzymatic $\mathrm{H}_{2} \mathrm{O}_{2}$ assays developed in recent years. Compared to the previously reported methods, the proposed sensor demonstrated more sensitive detection capabilities with improved linear range and detection limits.

To verify the selectivity of this sensor, seven common interferents were selected instead of $\mathrm{H}_{2} \mathrm{O}_{2}$ in $\mathrm{CL}$ assay, including glucose, glycine, NADH, sodium hypochlorite, sodium nitrite, uric acid, and lactic acid. The concentration of these

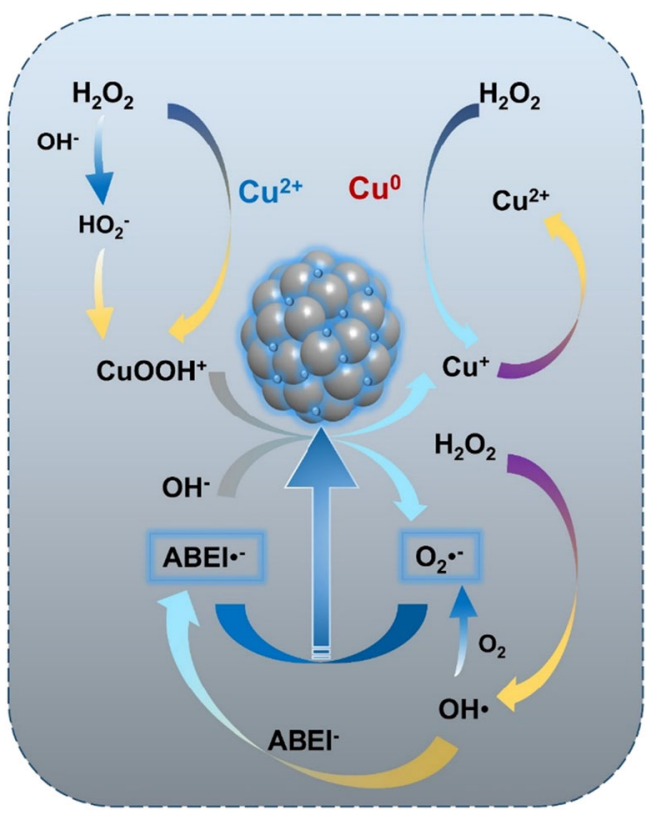

Fig. 6 Diagram of the possible CL mechanism of $\mathrm{ABEI} / \mathrm{CuFe}_{2} \mathrm{O}_{4}$ 

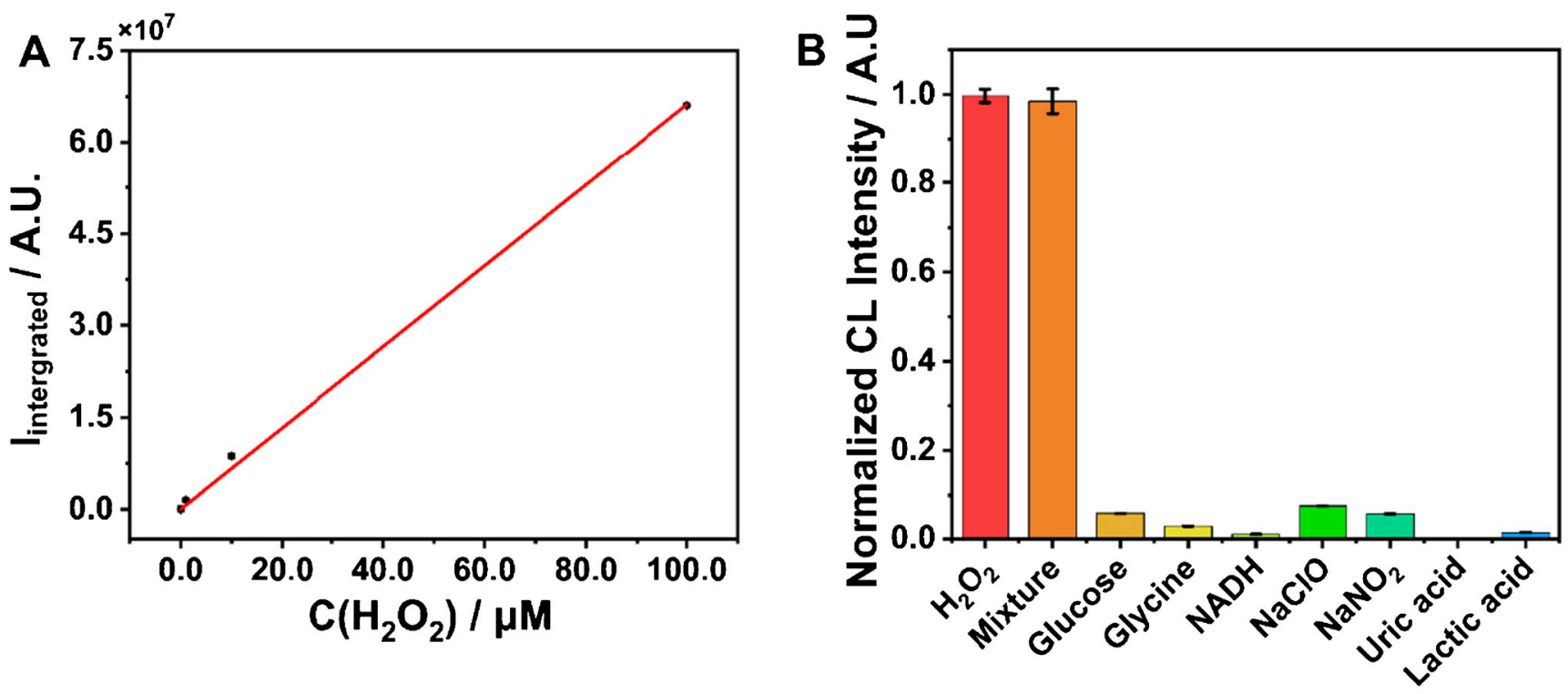

Fig. 7 A Linear relationship between the CL intensity and the concentration of $\mathrm{H}_{2} \mathrm{O}_{2}$. B Comparison of the CL signal response of $\mathrm{ABEI} / \mathrm{CuFe} \mathrm{O}_{4}$ for different substances

species $\left(1.0 \times 10^{-5} \mathrm{M}\right)$ was set to 10 times the concentration of $\mathrm{H}_{2} \mathrm{O}_{2}$ to be measured. As shown in Fig. 7B, the strong CL response of our nanomaterials occurred only in the presence of $\mathrm{H}_{2} \mathrm{O}_{2}$, which clearly illustrated the excellent selectivity of the proposed sensor.

$\mathrm{H}_{2} \mathrm{O}_{2}$ has played an important role in biological signal transduction pathways. It has been closely associated with the occurrence and development of tumors as well as some inflammatory diseases. Generally, $\mathrm{H}_{2} \mathrm{O}_{2}$ expresses at a high level in some cancers or during chronic inflammation [36-38]. Clinically, the detection of $\mathrm{H}_{2} \mathrm{O}_{2}$ is helpful for tumor diagnosis. Therefore, lung cancer was chosen as a model to explore the applicability of the sensor in human serum samples. Before the assay, human serum samples, including healthy human serum samples and lung cancer patient serum samples, were collected and diluted 100 times, and then purified by centrifugation using an ultrafiltration tube to thoroughly remove precipitates. The results are summarized in Table 1. The sensor could efficiently discriminate healthy and lung cancer patients. The sample recoveries ranged from 99.4 to
$105.2 \%$, confirming that the sensor might be applied for the detection of real human serum samples.

\section{Conclusion}

In this work, a new kind of CL functionalized magnetic nanomaterials with unique catalytic activity was synthesized. Firstly, the $\mathrm{CuFe}_{2} \mathrm{O}_{4}$ nanomaterials were prepared by a simple solvothermal method, and then reacted with ABEI to form $\mathrm{ABEI} / \mathrm{CuFe}_{2} \mathrm{O}_{4}$. The synthesized $\mathrm{ABEI} / \mathrm{CuFe}_{2} \mathrm{O}_{4}$ was quasispherical with a rough surface, and the average particle size was $97.5 \pm 7.2 \mathrm{~nm}$. The $\mathrm{ABEI} / \mathrm{CuFe}_{2} \mathrm{O}_{4}$ nanomaterials without additional catalysts showed unique CL properties, superior to $\mathrm{ABEI}-\mathrm{CuFe} \mathrm{O}_{4}$ in liquid phase. This reveals that the immobilization of $\mathrm{ABEI}$ on the surface of $\mathrm{CuFe}_{2} \mathrm{O}_{4}$ exhibits unique heterogeneous catalytic property. Moreover, the catalytic ability of $\mathrm{CuFe}_{2} \mathrm{O}_{4}$ was better than that of $\mathrm{CoFe}_{2} \mathrm{O}_{4}$, $\mathrm{ZnFe}_{2} \mathrm{O}_{4}, \mathrm{MnFe}_{2} \mathrm{O}_{4}$, and $\mathrm{NiFe}_{2} \mathrm{O}_{4} \cdot \mathrm{CuFe}_{2} \mathrm{O}_{4}$ with peroxidase-like activity exposed a large amount of $\mathrm{Cu}$ elements on the surface, which opened up a $\mathrm{H}_{2} \mathrm{O}_{2}$ dual-route
Table. 1 Results of $\mathrm{H}_{2} \mathrm{O}_{2}$ assay in human serum samples ${ }^{\mathrm{a}}$

\begin{tabular}{llllll}
\hline Sample & & Initial & Added & Found & Recovery (\%) \\
\hline Healthy $\left(\times 10^{-9} \mathrm{~mol} / \mathrm{L}\right)$ & $\mathbf{1}$ & - & 50.0 & $52.0 \pm 0.4$ & 104.0 \\
& $\mathbf{2}$ & - & 50.0 & $51.6 \pm 0.6$ & 103.1 \\
& $\mathbf{3}$ & - & 50.0 & $49.9 \pm 0.3$ & 99.8 \\
Lung cancer $\left(\times 10^{-6} \mathrm{~mol} / \mathrm{L}\right)$ & $\mathbf{1}$ & $1.0 \pm 0.1$ & 50.0 & $52.0 \pm 3.8$ & 102.1 \\
& $\mathbf{2}$ & $6.3 \pm 0.3$ & 50.0 & $56.0 \pm 0.4$ & 99.4 \\
& $\mathbf{3}$ & $8.1 \pm 0.3$ & 50.0 & $61.1 \pm 1.1$ & 105.2 \\
\hline
\end{tabular}

${ }^{\text {a }}$ Mean value $\pm \mathrm{SD}$ of three independent experiments, $n=3$ 
synergistic catalysis, resulting in strong light emission. In addition, $\mathrm{ABEI} / \mathrm{CuFe}{ }_{2} \mathrm{O}_{4}$ demonstrated good superparamagnetism, which may be used to separate the sample matrix from target in bioassays. Finally, an enzyme-free sensor for $\mathrm{H}_{2} \mathrm{O}_{2}$ was developed. $\mathrm{H}_{2} \mathrm{O}_{2}$ could be detected from $10.0 \mathrm{nM}$ to $0.1 \mathrm{mM}$ with a low detection limit of $5.6 \mathrm{nM}$ and good selectivity. The sensor could be applied to determine $\mathrm{H}_{2} \mathrm{O}_{2}$ in real human serum samples. It is of great application potential in clinical diagnosis.

Supplementary Information The online version contains supplementary material available at https://doi.org/10.1007/s00216-021-03597-w.

Author contribution Yuyang Wu designed the nanomaterial, conducted experimental work, and wrote the original draft. Jue Wang contributed to the design of the study and revision of the manuscript. Hua Cui directed the study and wrote the manuscript.

Funding This research received support from a COVID-19 special task grant provided by the Chinese Academy of Sciences Clinical Research Hospital (Hefei) (Grant No. YD2060002008) and the National Natural Science Foundation of China (Grant Nos. 21804124 and 21874122).

\section{Declarations}

Ethics approval The research was approved by the Ethics Committee of Anhui Chest Hospital. All volunteers were informed of and agreed with the objectives of the study.

Conflict of interest Hua Cui is an editor for Analytical and Bioanalytical Chemistry, but was not involved in the peer review of this work. The authors declare no competing interests.

\section{References}

1. Zhong Y, Li J, Lambert A, Yang Z, Cheng Q. Expanding the scope of chemiluminescence in bioanalysis with functional nanomaterials. J Mater Chem B. 2019;7(46):7257-66.

2. He Y, Cui H. Synthesis of highly chemiluminescent graphene oxide/silver nanoparticle nano-composites and their analytical applications. J Mater Chem. 2012;22(18):9086-91.

3. Huang Y, Gao L, Cui H. Assembly of multifunctionalized gold nanoparticles with chemiluminescent, catalytic, and immune activity for label-free immunoassays. ACS Appl Mater Interfaces. 2018;10(20):17040-6.

4. Cui H, Wang W, Duan C-F, Dong Y-P, Guo J-Z. Synthesis, characterization, and electrochemiluminescence of luminol-reduced gold nanoparticles and their application in a hydrogen peroxide sensor. Chem Eur J. 2007;13(24):6975-84.

5. Yu H, Long D. Highly chemiluminescent metal-organic framework of type MIL-101(Cr) for detection of hydrogen peroxide and pyrophosphate ions. Microchim Acta. 2016;183(12):3151-7.

6. Wang W, Ouyang H. Luminol-reduced Au nanoparticles-based dual-signal immunochromatographic test strip for pesticide residues. Microchem J. 2019;149:104055.

7. Liu Y, Haghighatbin MA, Shen W, Cui H. Functionalized polydopamine nanospheres with chemiluminescence and immunoactivity for label-free copeptin immunosensing. ACS Appl Nano Mater. 2020;3(5):4681-9.
8. Hun X, Meng Y, Wang S, Zhang H, Luo X. Mismatched catalytic hairpin assembly coupling hydroxylamine-O-sulfonic acid as oxide for DNA assay. Sensors Actuators B Chem. 2018;254:347-53.

9. Gao L, He X, Ju L, Liu X, Li F, Cui H. A label-free method for the detection of specific DNA sequences using gold nanoparticles bifunctionalized with a chemiluminescent reagent and a catalyst as signal reporters. Anal Bioanal Chem. 2016;408(30):8747-54.

10. Zhu X, Zhao H, Niu X, Liu T, Shi L, Lan M. A comparative study of carbon nanotube supported $\mathrm{MFe}_{2} \mathrm{O}_{4}$ spinels $(\mathrm{M}=\mathrm{Fe}, \mathrm{Co}, \mathrm{Mn})$ for amperometric determination of $\mathrm{H}_{2} \mathrm{O}_{2}$ at neutral $\mathrm{pH}$ values. Microchim Acta. 2016;183(8):2431-9.

11. Frey NA, Peng S, Cheng K, Sun S. Magnetic nanoparticles: synthesis, functionalization, and applications in bioimaging and magnetic energy storage. Chem Soc Rev. 2009;38(9):2532-42.

12. Su L, Qin W, Zhang H, Rahman ZU, Ren C, Ma S, et al. The peroxidase/catalase-like activities of $\mathrm{MFe}_{2} \mathrm{O}_{4}(\mathrm{M}=\mathrm{Mg}, \mathrm{Ni}, \mathrm{Cu})$ MNPs and their application in colorimetric biosensing of glucose. Biosens Bioelectron. 2015;63:384-91.

13. Chaibakhsh N, Moradi-Shoeili Z. Enzyme mimetic activities of spinel substituted nanoferrites $\left(\mathrm{MFe}_{2} \mathrm{O}_{4}\right)$ : a review of synthesis, mechanism and potential applications. Mater Sci Eng C. 2019;99: 1424-47.

14. Bi S, Zhou H, Zhang S. A novel synergistic enhanced chemiluminescence achieved by a multiplex nanoprobe for biological applications combined with dual-amplification of magnetic nanoparticles. Chem Sci. 2010;1(6):681-7.

15. Yang N, Huang Y, Ding G, Fan A. In situ generation of prussian blue with potassium ferrocyanide to improve the sensitivity of chemiluminescence immunoassay using magnetic nanoparticles as label. Anal Chem. 2019;91(7):4906-12.

16. Zhao H, Lin Q, Huang L, Zhai Y, Liu Y, Deng Y, et al. Ultrasensitive chemiluminescence immunoassay with enhanced precision for the detection of $\mathrm{cTnI}$ amplified by acridinium esterloaded microspheres and internally calibrated by magnetic fluorescent nanoparticles. Nanoscale. 2021;13(5):3275-84.

17. Yang R, Liu S, Cui H. Highly chemiluminescent magnetic mesoporous carbon composites $\mathrm{Fe}_{3} \mathrm{O}_{4} @$ void@C with yolk-shell structure. Sci China Chem. 2018;61(9):1143-50.

18. Kong W, Zhao X, Zhu Q, Gao L, Cui H. Highly chemiluminescent magnetic beads for label-free sensing of 2,4,6-trinitrotoluene. Anal Chem. 2017;89(13):7145-51.

19. Liu X, Li Q, Shu J, Cui H. N-(4-Aminobutyl)-N-ethylisoluminol/ $\mathrm{CoFe}_{2} \mathrm{O}_{4} /$ graphene hybrids with unique chemiluminescence and magnetism. J Mater Chem C. 2017;5(30):7612-20.

20. Wu H, Zhao M, Li J, Zhou X, Yang T, Zhao D, et al. Novel protease-free long-lasting chemiluminescence system based on the Dox-ABEI chimeric magnetic DNA hydrogel for ultrasensitive immunoassay. ACS Appl Mater Interfaces. 2020;12(42):47270-7.

21. Jiang $X$, Wang $H$, Wang $H$, Zhuo $Y$, Yuan R, Chai $Y$. Electrochemiluminescence biosensor based on 3-D DNA nanomachine signal probe powered by protein-aptamer binding complex for ultrasensitive mucin 1 detection. Anal Chem. 2017;89(7): 4280-6.

22. He SH, Shi WB, Zhang XD, Li JA, Huang YM. Betacyclodextrins-based inclusion complexes of $\mathrm{CoFe}_{2} \mathrm{O}_{4}$ magnetic nanoparticles as catalyst for the luminol chemiluminescence system and their applications in hydrogen peroxide detection. Talanta. 2010;82(1):377-83.

23. Shi $\mathrm{W}$, Zhang $\mathrm{X}$, He S, Huang $\mathrm{Y}$. $\mathrm{CoFe}_{2} \mathrm{O}_{4}$ magnetic nanoparticles as a peroxidase mimic mediated chemiluminescence for hydrogen peroxide and glucose. Chem Commun. 2011;47(38):10785-7.

24. Zheng J, Lin Z, Liu W, Wang L, Zhao S, Yang H, et al. One-pot synthesis of $\mathrm{CuFe}_{2} \mathrm{O}_{4}$ magnetic nanocrystal clusters for highly specific separation of histidine-rich proteins. J Mater Chem B. 2014;2(37):6207-14. 
25. Bao N, Shen L, Wang Y, Padhan P, Gupta A. A facile thermolysis route to monodisperse ferrite nanocrystals. J Am Chem Soc. 2007;129(41):12374-5.

26. Solano E, Perez-Mirabet L, Martinez-Julian F, Guzmán R, Arbiol J, Puig T, et al. Facile and efficient one-pot solvothermal and microwave-assisted synthesis of stable colloidal solutions of $\mathrm{MFe}_{2} \mathrm{O}_{4}$ spinel magnetic nanoparticles. J Nanopart Res. 2012;14(8): 1034.

27. Xiong W, Zeng Z, Li X, Zeng G, Xiao R, Yang Z, et al. Multiwalled carbon nanotube/amino-functionalized MIL-53(Fe) composites: remarkable adsorptive removal of antibiotics from aqueous solutions. Chemosphere. 2018;210:1061-9.

28. Emamian S, Lu T, Kruse H, Emamian H. Exploring nature and predicting strength of hydrogen bonds: a correlation analysis between atoms-in-molecules descriptors, binding energies, and energy components of symmetry-adapted perturbation theory. J Comput Chem. 2019;40(32):2868-81.

29. Liu M, Zhang H, Shu J, Liu X, Li F, Cui H. Gold nanoparticles bifunctionalized by chemiluminescence reagent and catalyst metal complexes: synthesis and unique chemiluminescence property. Anal Chem. 2014;86(6):2857-61.

30. Liu Y, Guo Z, Li F, Xiao Y, Zhang Y, Bu T, et al. Multifunctional magnetic copper ferrite nanoparticles as Fenton-like reaction and near-infrared photothermal agents for synergetic antibacterial therapy. ACS Appl Mater Interfaces. 2019;11(35):31649-60.

31. Perez-Benito JF. Reaction pathways in the decomposition of hydrogen peroxide catalyzed by copper(II). J Inorg Biochem. 2004;98(3): 430-8.

32. Qin Q, Liu Y, Li X, Sun T, Xu Y. Enhanced heterogeneous Fentonlike degradation of methylene blue by reduced $\mathrm{CuFe}_{2} \mathrm{O}_{4}$. $\mathrm{RSC} \mathrm{Adv}$. 2018;8(2):1071-7.

33. Yang H, Liu J, Feng X, Nie F, Yang G. A novel copper-based metal-organic framework as a peroxidase-mimicking enzyme and its glucose chemiluminescence sensing application. Anal Bioanal Chem. 2021;413(17):4407-16.

34. Dickinson BC, Chang CJ. Chemistry and biology of reactive oxygen species in signaling or stress responses. Nat Chem Biol. 2011;7(8):504-11.

35. Asif M, Liu H, Aziz A, Wang H, Wang Z, Ajmal M, et al. Coreshell iron oxide-layered double hydroxide: high electrochemical sensing performance of $\mathrm{H}_{2} \mathrm{O}_{2}$ biomarker in live cancer cells with plasma therapeutics. Biosens Bioelectron. 2017;97:352-9.

36. Zhang H, Ruan J, Liu W, Jiang X, Du T, Jiang H, et al. Monitoring dynamic release of intracellular hydrogen peroxide through a microelectrode based enzymatic biosensor. Anal Bioanal Chem. 2018;410(18):4509-17.

37. Ren H, Long Z, Cui MC, Shao K, Zhou KX, Ouyang J, et al. Dualfunctional nanoparticles for in situ sequential detection and imaging of ATP and $\mathrm{H}_{2} \mathrm{O}_{2}$. Small. 2016;12(29):3920-4.

38. Goddu RN, Henderson CF, Young AK, Muradian BE, Calderon L, Bleeg LH, et al. Chronic exposure of the RAW246.7 macrophage cell line to $\mathrm{H} 2 \mathrm{O} 2$ leads to increased catalase expression. Free Radic Biol Med. 2018;126:67-72.

Publisher's note Springer Nature remains neutral with regard to jurisdictional claims in published maps and institutional affiliations.

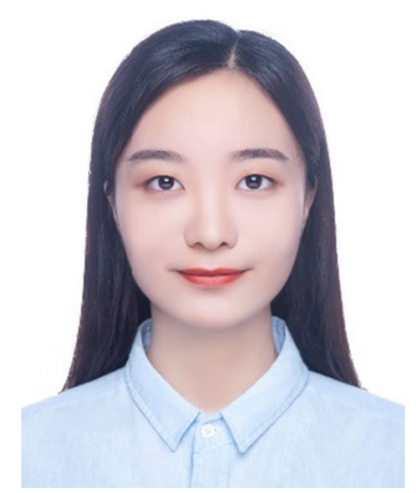

Yuyang $\mathbf{W u}$ is currently a master's graduate student in the School of Chemistry and Materials Science, University of Science and Technology of China. She specializes in chemiluminescent functionalized nanomaterials and their applications in sensors.

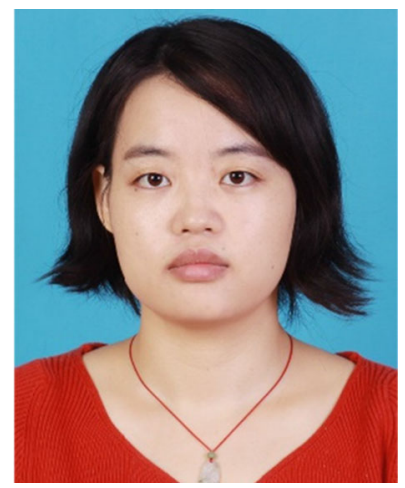

Jue Wang received her Ph.D. degree from the University of Science and Technology of China under the supervision of Prof. Hua Cui in 2020. In the same year, she continued her postdoctoral research at the research group of Prof. Hua Cui. Her research interests focus on the development of nanostructured materials and their applications in bioassays.

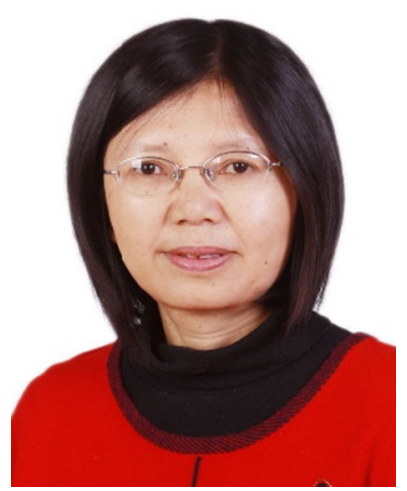

Hua Cui is currently Professor of Analytical Chemistry at the University of Science and Technology of China. She received her Ph.D. degree from the University of Science and Technology of China in 1990. Her research interests are analytical chemiluminescence (CL) and electrochemiluminescence (ECL), and their applications in interdisciplinary fields including public health, food safety, and environmental monitoring. 